\title{
Evaluation of PECAM-1 and p38 MAPK expressions in cerebellum tissue of rats treated with caffeic acid phenethyl ester: a biochemical and immunohistochemical study
}

\author{
A. Çetin 1, E. Deveci² \\ ${ }^{1}$ Department of Neurosurgery, University of Health Sciences, Gazi Yaşargil Education and Research Hospital, \\ Diyarbakır, Turkey \\ 2Department of Histology and Embryology, Faculty of Medicine, Dicle University, Diyarbakır, Turkey \\ [Received: 7 June 2018; Accepted: 16 July 2018]
}

Background: This study aimed to investigate the antioxidative and anti-inflammatory effects of caffeic acid phenethyl ester (CAPE) on damage caused to cerebellum tissue by diffuse traumatic head trauma via biochemical, histopathologic, and immuno-histochemical methods.

Materials and methods: Male Sprague-Dawley (300-350 g) rats were subjected to traumatic brain injury with a weight-drop device (300 g/1 m weight-height impact). Twenty-four adult rats were randomly divided into three equal groups of 8 , including a control group, traumatic brain injury (TBI) group, and TBI + CAPE treatment group (10 $\mathrm{mmoL} / \mathrm{kg} / \mathrm{i}$. . .). Cerebellum tissue samples taken from anterior lobe from all rats were taken 7 days after traumatic injury and were subjected to biochemical and histopathological analysis, as well as immunohistochemical analysis for platelet endothelial cell adhesion molecule-1 (PECAM-1) and phosphate 38-mitogen-activated protein kinase (p38 MAPK).

Results: In the TBI group, the granular layer had dilatation and haemorrhage in the capillary vessels and inflammatory cell infiltration around the periphery of the blood vessels. In the TBI + CAPE group, the small capillaries in the white matter were slightly dilated, there were no inflammatory cells, and dense chromatin/ granular cells were observed in the granular layer. Also in the TBI + CAPE group, the Purkinje cells of the ganglion cell layer had ovoid nuclei, were chromatin-rich, and their extensions protruded to the molecular layer. CAPE is thought to regulate inflammation, cell damage, and angiogenetic development by affecting the PECAM-1 and p38 MAPK proteins.

Conclusions: These proteins are key modulators of endothelial integrity and neuroinflammation in vessels in response to endothelial damage as well as of the proinflammatory response in the cerebellum in response to traumatic damage. (Folia Morphol 2019; 78, 2: 221-229)

Key words: traumatic brain injury, cerebellum, PECAM-1, p38 MAPK, rat 


\section{INTRODUCTION}

The cerebellum is vulnerable to damage from a variety of sources, including developmental defects, degenerative diseases, infectious processes, chronic alcoholism, trauma, and tumours [35]. Caffeic acid phenethyl ester (CAPE) is a flavonoid-like compound that is the active component of propolis, which is obtained from honey bee hives and has been longused in traditional medicine. It has many protective properties, including antioxidant, anti-inflammatory, anti-carcinogenic, antiviral, neuroprotective, and immunomodulation [3]. Research in a number of traumatic brain injury (TBI) animal models has shown that pathophysiological changes in the cortex, thalamus, and hippocampus contribute to motor and cognitive disorders. Impairments in motor function, coordination, and cerebellar function are common outcomes of TBI [36]. Some of the classically described consequences of direct traumatic injury to the cerebellum are hypotonia, ataxia, dysmetria, tremor, and vertigo [38]. Cells from various brain regions respond differently to mechanical injury and it is known that the Purkinje neurons are the cells most affected by cerebellar trauma [4].

Among the many signalling pathways that respond to mitogens and stress factors, mitogen-activated protein kinase (MAPK) family members are crucial for cell repair by regulating the activities of nuclear transcription factors $[43,53,61]$. There are three known types of MAPKs: ERKs, SAPK/JNKs and p38 MAPKs. Initially, ERKs were found to be important for cell survival, SAPK/JNKs and p38 MAPKs were more likely to be stressed and thus play a role in apoptosis $[27,28,52,57]$. The magnitude of the balance between ERK and SAPK/JNK/p38 MAPK activation is assumed to be a key to whether cells continue to survive or whether apoptosis has entered. However, many researchers have recently shown that the regulation of apoptosis by MAPKs is more complex than originally thought $[11,27,33,52]$. Mitogen-activated protein kinases are a highly conserved family of serine/threonine protein kinases involved in a variety of fundamental cellular processes such as proliferation, differentiation, motility, stress response, apoptosis, and survival. Conventional MAPKs include the extracellular signal-regulated kinase 1 and 2 (Erk1/2 or p44/42) $[22,48]$, the c-Jun $\mathrm{N}$-terminal kinases 1-3 (JNK1-3)/stress activated protein kinases (SAPK1A, 1B, 1C) $[63,65]$, the $p 38$ isoforms (p38 $\alpha, \beta, \gamma$, and $\delta)$, and Erk5 [21, 44]. The lesser-studied, atypical MAPKs include Nemo-like kinase (NLK), Erk3/4, and Erk7/8 [20].
Experimental studies suggest that the phosphate 38 mitogen-activated protein kinase signalling pathway plays a major role in ischaemia-reperfusion injury. An increase in p38 MAPK expression in kidney, liver, vascular and myocardial cells and pulmonary ischaemia-reperfusion models has been reported $[2,40,50,62]$. Additionally, it has been reported that MAPK participates in the control of complex cellular processes, such as gene expression, synaptic plasticity in the nervous system, cell differentiation, cell proliferation, cell death, and inflammation [20,31]. The MAPK pathway is an evolutionarily conserved mechanism of transducing external stress and injury to internal cellular responses; these responses play a major role in the balance between cell survival and cell death $[55,58]$. Platelet endothelial cell adhesion molecule-1 (PECAM-1) is a restricted receptor in blood and vascular cells [39].

There are five members of the immunoglobulin superfamily. It has been shown that intracellular adhesion molecule-1 and -2 (ICAM-1, ICAM-2), vascular adhesion molecule-1 (VCAM-1), PECAM-1, mucosal vascular addressing cell adhesion molecule-1 (MAdCAM-1). PECAM-1 has been reported to play an important role in endothelial cells and in leukocyte adhesion to transduction. MAdCAM-1, a ligand of L-selectin and a4P7 integrin, has been reported to play a key role in the selective targeting of lymphocytes $[17,47]$. Furthermore, it has also been shown that ICAM-1, VCAM-1 and PECAM-1 serve as signal transducers not only for the transendothelial migration of leukocytes but also for inducing endothelial signalling and influencing the progression of neuroinflammation [18]. Among the molecules known to (secondarily) activate the integrins are the chemokines and PECAM-1, CD31 or endoCAM. Once a leukocyte binds to endothelium via an integrin-immunoglobulin (Ig) superfamily (IgSF) interaction, it "searches" for junctions between endothelial cells, first squeesing between these potential discontinuities, and then penetrating the underlying basement membrane to reach the tissues $[42,64]$. Mouse CD31 has also been isolated and found to be $63 \%$ identical at the aa level to human CD31 [59]. While monoclonal antibodies to CD31 are reportedly species specific [59], polyclonal antibodies to CD31 seem to show species cross-reactivity [34]. PECAM-1 plays a critical role in damage recovery after pathological conditions. The function of PECAM-1 in endothelial cells in the context of inflammation and apoptosis has been investigated $[29,56]$. It is not known that PECAM- 1 is exercised on 
neurons or glia [13]. In the brain, PECAM-1 has been reported to be exclusively in cerebral endothelial cells forming the blood-brain barrier [30].

The current study aimed to investigate the antioxidative and anti-inflammatory effects of CAPE on damage caused to the cerebellum tissue by diffuse traumatic head trauma via biochemical, histopathologic, and immunohistochemical methods.

\section{MATERIALS AND METHODS}

\section{Animals}

Every single surgical methodology and the consequent care and healing of the animals utilised as a part of this investigation were in strict understanding with the National Institutes of Health (NIH Publications No. 8023, revised 1978) rules for animal care. All techniques performed in this examination were approved by the Ethics Committee for Animal Experimentation of the Faculty of Medicine at Dicle University, Turkey (Protocol number: 2017-32). Twenty-four male Sprague-Dawley rats (300-350 g) were maintained under $23 \pm 2^{\circ} \mathrm{C}$ and $12 \mathrm{~h} \mathrm{light/dark}$ cycles with ad libitum access to standard pelleted food and water.

All rats toward the finish of the analysis were healthy and no distinction in nourishment/water consumption and body weight pick up amongst experimental and control rats were noticed. The rats were divided into three equal groups as control, trauma (TBI), and trauma (TBI) + CAPE.

\section{Traumatic brain injury model}

Sedation procedure. The animals were anesthetised via an intraperitoneal injection of $5 \mathrm{mg} / \mathrm{kg}$ xylazine $\mathrm{HCl}$ (Rompun, Bayer HealthCare AG, Germany) and $40 \mathrm{mg} / \mathrm{kg}$ ketamine $\mathrm{HCl}$ (Ketalar, Pfizer Inc., USA) [45], after which they were allowed to breathe spontaneously.

Control group. Isotonic saline solution (an equal volume of (APE) was administered i.p. for 7 days.

TBI group. The diffuse brain injury model described by Marmarou et al. [32] was used Briefly, a trauma device dropped a constant weight $(300 \mathrm{~g})$ from a specific height $(1 \mathrm{~m}$ ) through a tube, inducing mild trauma. Following trauma, the rats' cerebellum tissues were removed.

TBI + CAPE group. $15 \mathrm{~min}$ following injury, the rats were given CAPE $(10 \mu \mathrm{moL} / \mathrm{kg} / \mathrm{i} . \mathrm{p})$ intraperitoneally every day for 7 days [26]. At the end of the study, animals were sacrificed and cerebellum tissues were removed. Blood samples were collected from the inferior vena cava for serum biochemical markers determination in all groups. In this way, MDA, SOD, CAT, and GSH-x values were measured biochemically. And, cerebellum tissue taken from anterior lobe was extracted, fixed in a $10 \%$ formalin solution, and embedded in paraffin blocks for histopathologic examination in all groups. Sections $(5 \mu \mathrm{m}$ thick) were obtained from paraffin blocks and stained with haematoxylin and eosin (H\&E).

\section{Immunohistochemistry method}

Antigen retrieval process was performed in citrate buffer solution $(\mathrm{pH} \mathrm{6})$ two times first $5 \mathrm{~min}$, later $4 \mathrm{~min}$ boiled in microwave oven at $700 \mathrm{~W}$ (Bosch ${ }^{\circledR}$ ). They were allowed to cool to room temperature for $20 \mathrm{~min}$ and washed in distilled water for $5 \mathrm{~min}$ two times. Endogenous peroxidase activity was blocked in $0.1 \%$ hydrogen peroxide [K-40677109,64271 hydrogen peroxide $\left(\mathrm{H}_{2} \mathrm{O}_{2}\right)$, Dortmudt + Germany, MERCK] ( $3 \mathrm{~mL}$ $30 \%$ hydrogen peroxide $\left(\mathrm{H}_{2} \mathrm{O}_{2}\right)+27 \mathrm{~mL}$ methanol) for $10 \mathrm{~min}$. Ultra $\vee$ block (Histostain-Plus Kit, Invitrogen, Carlsbad, CA) was applied for 8 min prior to the application of primary antibodies $\mathrm{p} 38$ MAPK mouse monoclonal, 1/100 and PECAM-1 mouse monoclonal, 1/100 for overnight. Secondary antibody (HistostainPlus Kit, Invitrogen, Carlsbad, CA) was applied for $20 \mathrm{~min}$. Slides then were exposed to streptavidin-peroxidase for $25 \mathrm{~min}$. Diaminobenzidine (DAB, Invitrogen, Carlsbad, lot: HD36221, Thermo Fischer, Fremont, CA, USA) was used as a chromogen. Control slides were prepared as mentioned above but omitting the primary antibodies. After counterstaining with haematoxylin (product number: HHS32 SIGMA, Haematoxylin Solution, Harris Modified, Sigma-Aldrich, 3050 Spruce Street, Saint Louis, MO 63103, USA), washing in tap water for $3 \mathrm{~min}$ and in distilled water for $2 \times 3 \mathrm{~min}$, the slides were mounted with Entellan ${ }^{\circledR}$ (lot: 107961, Sigma-Aldrich, St. Louis, MO, United States).

\section{Malondialdehyde and glutathione peroxidase assays}

Malondialdehyde (MDA) levels and glutathione peroxidase (GSH-Px) activities were determined in the cerebellum of each rat, and the average values of each group were calculated. Each cerebellum sample was prepared as a $10 \%$ homogenate (according to weight) in $0.9 \%$ saline using a homogenizer on ice. Then, the homogenate was centrifuged at $2000 \mathrm{rpm}$ for $10 \mathrm{~min}$, and the supernatant was collected. MDA levels were determined using the double heating method of Draper and Hadley [14]. MDA is an end product of fatty acid 
peroxidation that reacts with thiobarbituric acid (TBA) to form a coloured complex. Briefly, $2.5 \mathrm{~mL}$ of TBA solution (100 g/L) was added to $0.5 \mathrm{~mL}$ of homogenate in a centrifuge tube, and the tubes were placed in boiling water for $15 \mathrm{~min}$. After cooling with flowing water, the tubes were centrifuged at $1000 \mathrm{rpm}$ for $10 \mathrm{~min}$, and $2 \mathrm{~mL}$ of the supernatant was added to $1 \mathrm{~mL}$ of TBA solution $(6.7 \mathrm{~g} / \mathrm{L})$; these tubes were placed in boiling water for another $15 \mathrm{~min}$. After cooling, the amount of TBA-reactive species was measured at $532 \mathrm{~nm}$, and the MDA concentration was calculated using the absorbance coefficient of the MDA-TBA complex. MDA values were expressed as nanomoles per gram $(\mathrm{nmol} / \mathrm{g})$ of wet tissue.

The GSH-Px activity was measured by the method of Paglia and Valentine [37]. An enzymatic reaction was initiated by the addition of hydrogen peroxide $\left(\mathrm{H}_{2} \mathrm{O}_{2}\right)$ to a tube that contained reduced nicotinamide adenine dinucleotide phosphate, reduced glutathione, sodium azide, and glutathione reductase. The change in absorbance at $340 \mathrm{~nm}$ was monitored by spectrophotometry. Data were expressed as $\mathrm{U} / \mathrm{g}$ protein.

\section{Measurement of superoxide dismutase activity}

Total superoxide dismutase (SOD) activity was determined with a SOD detection kit (RANSOD kit, Randox (o., UK) according to the manufacturer's instructions. SOD accelerates the conversion of the toxic superoxide (produced during oxidative energy processes) to hydrogen peroxide and molecular oxygen. This method employs xanthine and xanthine oxidase to generate superoxide radicals that react with 2-(4-iodophenyl)-3-(4- nitrophenol)5-phenyltetrazolium chloride (INT) to form a red formazan dye. The SOD activity is measured by the degree of inhibition of this reaction. One unit of SOD causes $50 \%$ inhibition of the rate of reduction of INT under the assay's conditions. Absorbance measurements were taken at $505 \mathrm{~nm}$, and SOD levels were determined through a standard curve and expressed as $\mathrm{U} / \mathrm{mg}$ protein [49].

\section{Measurement of catalase activity}

Tissue catalase (CAT) activity was assayed spectrophotometrically by monitoring the decomposition of $\mathrm{H}_{2} \mathrm{O}_{2}$ using the procedure of Aebi [1]. Briefly, $0.5 \mathrm{~mL}$ of $30 \mathrm{mM} \mathrm{H}_{2} \mathrm{O}_{2}$ in $50 \mathrm{mM}$ phosphate buffer ( $\mathrm{pH} \mathrm{7.0)}$ was added to $1 \mathrm{~mL}$ of tissue supernatant (diluted 1:10), and the consumption of $\mathrm{H}_{2} \mathrm{O}_{2}$ was followed spectrophotometrically at $240 \mathrm{~nm}$ for $2 \mathrm{~min}$ at $25^{\circ} \mathrm{C}$. The molar extinction coefficient was $43.6 \mathrm{~L} / \mathrm{mol}$ per cm for $\mathrm{H}_{2} \mathrm{O}_{2}$. CAT activity was expressed as mmol $\mathrm{H}_{2} \mathrm{O}_{2}$ consumed/min per $\mathrm{mg}$ tissue protein.

\section{Statistical analysis}

All of the statistical analyses for this study were carried out using GraphPad Prism 4.0 software (GraphPad Software, 2003, San Diego, CA, USA). All data are presented as mean \pm standard deviation (SD). Groups of data were compared with an analysis of variance (ANOVA) followed by Tukey's multiple comparison test. Values of $p<0.05$ were considered significant.

\section{RESULTS}

\section{Biochemical findings}

The following biochemical parameters were compared between groups (Fig. 1).

\section{Tissue malondialdehyde levels}

Malondialdehyde values in the trauma (TBI) group were significantly higher than those of the control group ( $p<0.001$ ), while the TBI + CAPE group had significantly lower levels than those of the trauma (TBI) group ( $<<0.001)$.

\section{Tissue glutathione peroxidase levels}

Tissue glutathione peroxidase levels of the control group were significantly higher than those of the trauma group ( $p<0.001$ ), while those of the TBI + CAPE group were also significantly higher than those of the trauma group $(p<0.001)$.

\section{Superoxide dismutase levels}

Tissue SOD levels of the control group were significantly lower than those in the trauma group, while those of the TBI + CAPE group were significantly higher than those of the trauma group ( $p<0.001)$.

\section{Catalase levels}

Tissue CAT levels in the control group were significantly lower than those of the trauma group ( $p<0.001)$, while those of the TBI + CAPE group were significantly higher than those of the trauma group $(p<0.001)$.

\section{Histological findings}

In the control group, the Purkinje cells of the ganglion cell layer were in a horizontal and fibrillar structure. In the glomerular areas, the Purkinje cells were arranged regularly in a granular layer, and the microglia and basket cells were scattered diffusely in the molecular layer. In the granular layer of the 

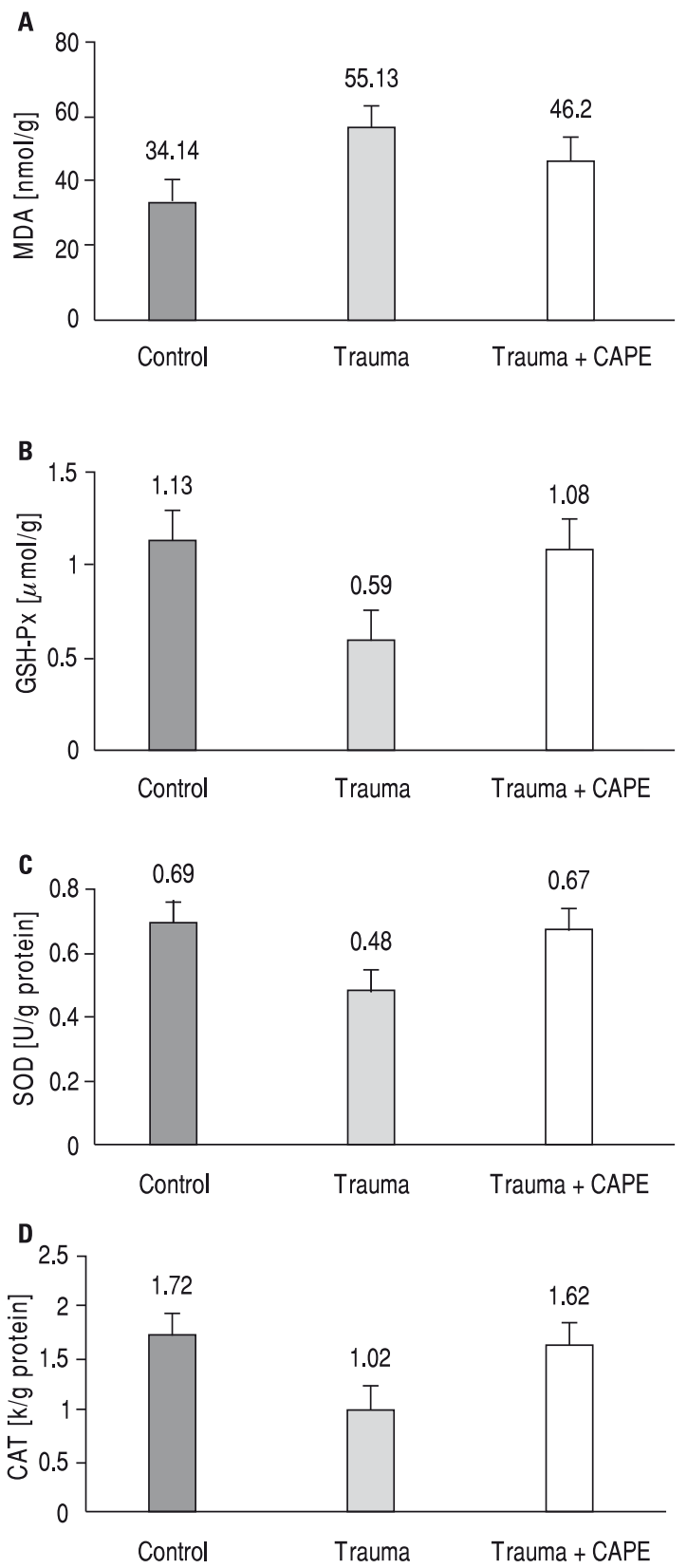

Figure 1. Biochemical results relevant to the study groups; A. MDA; B. GSH-Px; C. SOD; D. CAT. Abbreviations - see text.

trauma group, there was dilatation and haemorrhage in the capillary vessels as well as inflammatory cell infiltration around the periphery of the blood vessels. Degenerative changes in the Purkinje cells (i.e., pyknosis in some of the nuclei) were observed in the ganglion cell layer. In the TBI + CAPE group, the small capillaries were slightly dilated in the white matter. There were no inflammatory cells, dense chromatin/ granular cells were observed in the granular layer, and the Purkinje cells of the ganglion cell layer had ovoid nuclei with chromatin-rich extensions protruding to the molecular layer. Diffused microglia and basket cells were scattered in the molecular layer.

\section{Immunohistochemical findings}

In the control group, p38 MAPK expression was observed in some Purkinje cells of the ganglion cell layer and in the basket cells of the molecular layer. The TBI group had positive expression of p38 MAPK in inflammatory cells around the blood vessels in the granular layer and in the molecular layer boundary. p38 MAPK expression also was seen in the glial cells and in some apoptotic Purkinje cells. In the TBI + CAPE group, p38 MAPK was expressed in the Purkinje cells, but was not expressed in the small granular cells of the granular layer. There was no p38 MAPK expression in the microglia and basket cells. The control group had no PECAM-1 expression in the microglial cells and endothelial cells of the capillary vessels in the molecular layer; however, PECAM-1 expression was positive in the Purkinje cells. In the TBI group, PECAM-1 expression was positive in the endothelial cells of the dilated blood vessels between the ganglion layer and the granular layer, in inflammatory cells, as well as in some degenerate Purkinje cells. Expression of PECAM-1 was observed in the microglial and basket cells and in the degenerative fibres in the molecular layer. In the TBI + CAPE group, there was no PECAM-1 expression in the microglial and basket cells or in the endothelial cells of some dilated vessels in the molecular layer; however, PECAM-1 expression was positive in the Purkinje cells (Fig. 2).

\section{DISCUSSION}

Traumatic brain injury usually results in severe shock to the head and/or body. A minor traumatic brain injury can lead to the transient dysfunction of brain cells. Previous studies have shown that a variety of pathological factors (e.g., oxidative stress, the inflammatory response, and apoptosis) are involved in secondary brain injury following traumatic brain injury. Early interventions to reduce the level of oxidative stress and the extent of the inflammatory response can significantly reduce the extent of traumatic brain injury [19]. Activated microglia cells serve as cellular cleaners to alleviate traumatic damage and promote wound healing. It has been reported that these numbers may increase in cases of Purkinje cell damage [25]. 

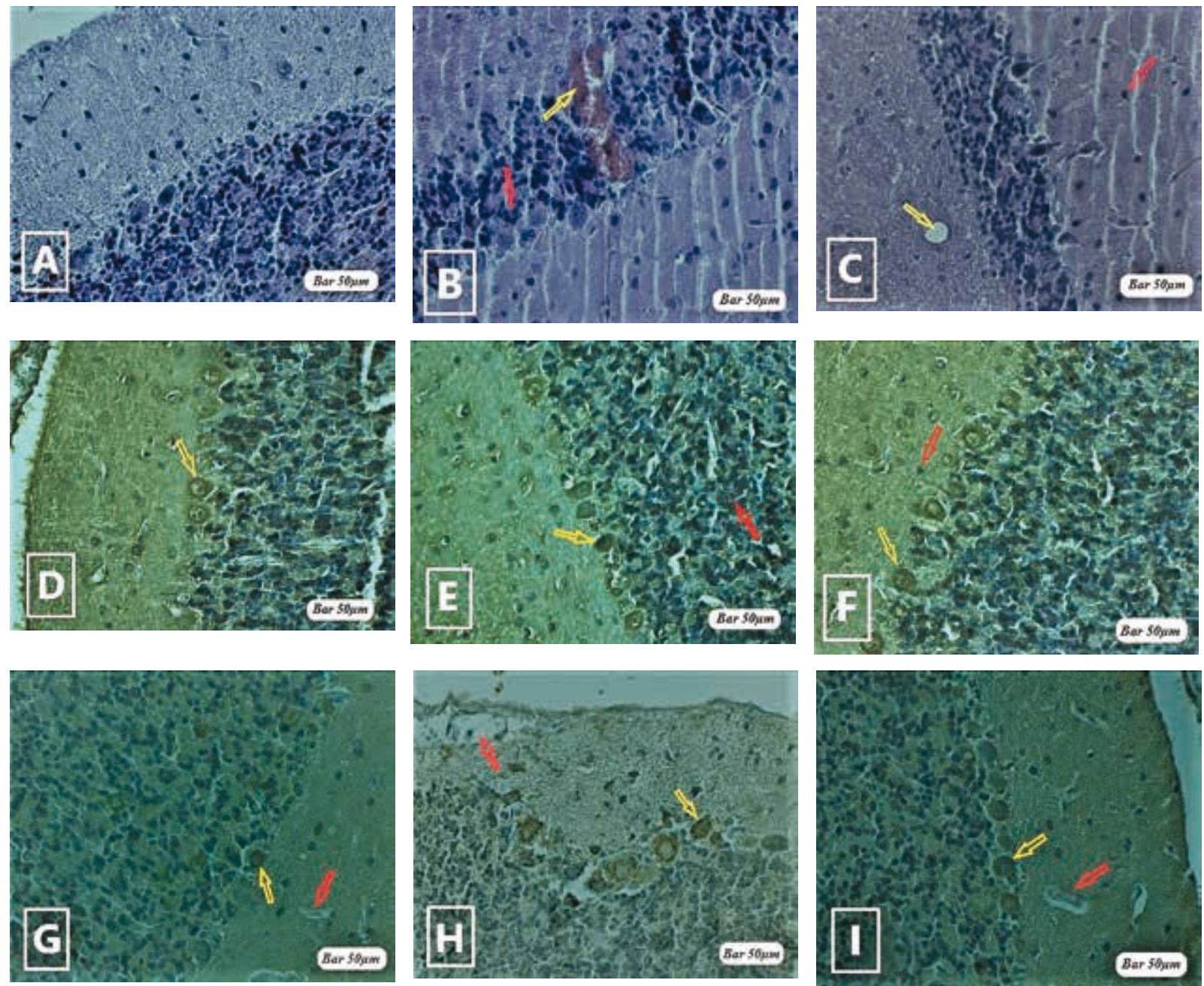

Figure 2. A. Control group. Purkinje cells in horizontal view, fibrillar structure and granular cells regular, basket in the molecular layer and microglia cells diffuse appearance. H\&E staining, bar $50 \mu \mathrm{m} ; \mathbf{B}$. Trauma group. Capillary dilatation of veins and haemorrhage and inflammatory cell infiltration around blood vessels (yellow arrow), Degenerative changes in pyknotic Purkinje cells in some nuclei of the ganglion cell layer (red arrow), H\&E staining, bar $50 \mu \mathrm{m} ;$ C. Trauma + CAPE group. Small dilation of small capillaries in white matter (yellow arrow). There are no inflammatory cells, dense chromatin cells in the granular layer, Purkinje cell of the ganglion cell layer, nuclei oval and chromatin rich appearance, and microglia and basket cells (red arrow). H\&E staining, bar $50 \mu \mathrm{m}$; D. Control group. p38 MAPK expression in some Purkinje cells of ganglion cell layer and in the basket cells of the molecular layer (yellow arrow). p38 MAPK immunostaining, bar $50 \mu \mathrm{m}$; E. Trauma group. Positive expression of p38 MAPK in inflammatory cells around the blood vessels in the granular layer and molecular layer (red arrow), also positive p38 MAPK expression in glial cells and some apoptotic Purkinje cells (yellow arrow). p38 MAPK immunostaining, bar $50 \mu \mathrm{m}$; F. Trauma + CAPE group. p38 MAPK expression in Purkinje cells (yellow arrow), but not expression in small granular cells of granular layer. Negative p38 MAPK expression in microglia and basket cells p38 MAPK (red arrow), p38 MAPK immunostaining, bar $50 \mu \mathrm{m}$; G. Control group. PECAM-1 expression negative in microglial cells and endothelial cells of the capillary vessels in the molecular layer (red arrow), positive PECAM-1 expression in Purkinje cells (yellow arrow). PECAM-1 immunostaining, bar $50 \mu \mathrm{m}$; $\mathbf{H}$. Trauma group. Positive PECAM-1 expression in the endothelial cells of dilated blood vessels between the ganglion layer (red arrow), the granular layer, in inflammatory cells and in some degenerate Purkinje cells (yellow arrow), expression of PECAM-1 in microglial and basket cells and degenerative fibres in the molecular layer. PECAM-1 immunostaining, bar $50 \mu \mathrm{m}$; I. Trauma + CAPE group. Negative PECAM-1 expression in microglial and basket cells and endothelial cells (red arrow), positive PECAM-1 expression in Purkinje cells (yellow arrow). PECAM-1 immunostaining, bar $50 \mu \mathrm{m}$. Abbreviations — see text.

In TBI models, regional specific cerebellar Purkinje cell injury and/or loss are important features that are known to cause cerebellar damage, including a distinct spatial regeneration of glia and traumatic axonal damage [38]. Fukuda et al. [16] examined an injury caused by frontoparietal cortex lateral fluid percussion at 1 day and 7 days after injury. At both time points, they reported death of Purkinje cells in the cerebellar vermis.
Traumatic brain injury causes glial cell activation in the cerebellum, and changes in the Purkinje cells are important for determining the extent of damage. Following selective and diffuse TBI, the cerebellum exhibits pathological changes, including selective cell loss, altered metabolism, and white matter damage $[38,46]$. Damage to the Purkinje cells is considered an indicator of TBI [25]. In our 
current study, the TBI group had dilatation in the capillary vessels and inflammatory cell infiltration around the haemorrhage in the granular layer. The Purkinje cells revealed degenerative changes with some pyknotic nuclei in the ganglion cells. In the TBI + CAPE group, it was observed slightly dilated small capillaries (especially in white matter), and the granular cells were chromatin-rich with no inflammation. The Purkinje cells in the ganglion layer have chromatin-rich, oval-shaped nuclei, and their cytoplasmic extensions extend into the molecular layer. In addition, it was seen small and diffuse microglia and basket cells. In the ganglion cell layer, the nuclei of the Purkinje cells were ovoid and chromatin-rich, and their extensions protruded to the molecular layer. Microglia and basket cells were diffuse through the molecular layer.

Caffeic acid phenethyl ester has been reported to block many inflammatory agents (primarily tumour necrosis factor alpha) by blocking nuclear factor kappa B (NF- $\kappa$ B) and oxygen radicals. It has also been shown that CAPE inhibits apoptosis in inflammatory cells independent of glucocorticoid receptors [10]. To determine the molecular effects of CAPE, it was investigated changes in p38 MAPK and PECAM-1 expression in cerebellum tissue in traumatic brain injured rats. Most mRNAs coding for inflammatory response genes are unstable and stabilised by the p38 MAPK pathway $[5,54]$. It is known that microglia respond quickly (30 $\mathrm{min}$ ) and migrate immediately to the wound centre. MAPK p38 $\alpha$ helps to bind inflammatory stimuli in the microglia in response to cellular activities. Sustained activation of $\mathrm{p} 38 \alpha$ MAPK was observed in activated microglia in the brain after cerebral brain ischaemia [24]. Furthermore, Haines et al. [20]. revealed that MAPK signalling pathways regulate myelination. In our current study's TBI group, p38 MAPK was expressed in the inflammatory cells around the blood vessels in the granular layer and in the molecular layer boundary. Additionally, positive p38 MAPK expression was seen in the glial cells and in some apoptotic Purkinje cells. Results of the TBI + CAPE group revealed that p38 MAPK was not expressed in the small granular cells of the granular layer or in the microglial and basket cells. However, the Purkinje cells positively expressed p38 MAPK. It was hypothesized that CAPE regulates the common inflammatory response observed after cerebellum injury, thus leading to re-activation of the microglial and Purkinje cells (Fig. 2E, F).
Vascular endothelial cells that cross the endothelial cell-cell junction during inflammatory processes have been shown to play an important role in vascular regulation. These cells have the ability to modulate PECAM-1 intracellular signalling processes $[39,60]$. During recovery of ischaemic damage, PECAM-1 has been shown to regenerate angiogenic and antiapoptotic isoforms, as well as repair and remodel the damaged blood-brain barrier [12, 15]. PECAM1-mediated activation of the PI3K/Akt pathway upregulates $\mathrm{NF}-\kappa \mathrm{B}$-mediated transcription to facilitate angiogenesis, cell survival/growth, and the recovery of the endothelial cell barrier [8, 9]. Hwang et al. [23] observed that transient ischaemia produced in gerbils by 5 -min occlusion of both common carotid arteries results in a significant increase of PECAM-1 immunoreactivity and protein level in hippocampus proper. And, they reported that PECAM-1 immunoreactivity in post-ischaemic group was significantly increased by 4 days after ischaemic insult. Rosenblum et al. [41] suggested that anti-PECAM-1 treatment may be effective in inhibiting the in vivo inhibition of platelet adhesion/aggregation at the site of endothelial injury in brain arterioles. Vaporciyan et al. [51] have shown that human PECAM-1 antibody cross-reacting with rat PECAM-1 can block the in vivo accumulation of rat neutrophils in the peritoneal cavity and the alveolar part of the lung. The authors of this trial also suggested that PECAM-1 might be a potential therapeutic target. TBI may be expected to increase the expression of PECAM-1 on vascular endothelium in the traumatised brain, which is constantly followed by an acute inflammatory response. However, Carlos et al. [7] showed that PECAM-1 expression remained unchanged in a rat model.

\section{CONCLUSIONS}

It was hypothesized that PECAM-1 expression contributes to the development of angiogenesis after endothelial damage. In addition, it was thought that CAPE administration inhibits the progression of the inflammatory reaction in endothelial cells, which was initially induced by proinflammatory processes. CAPE administration is thought to regulate inflammation, cell damage, and angiogenetic development by affecting the PECAM-1 and P38 MAPK proteins. These proteins are key modulators of endothelial integrity and neuroinflammation in vessels in response to endothelial damage, and are key regulators of the proinflammatory response occurring in the cerebellum in response to traumatic damage. 


\section{REFERENCES}

1. Aebi HE. Catalase. In: Bergmeyer HU (eds). Methods of enzymatic analysis. 3rd edn. Verlag Chemie, Germany 1983: 273-286.

2. Arumugam S, Girish Subbiah K, Kemparaju K, et al. Neutrophil extracellular traps in acrolein promoted hepatic ischemia reperfusion injury: Therapeutic potential of NOX2 and p38MAPK inhibitors. J Cell Physiol. 2018; 233(4): 3244-3261, doi: 10.1002/jcp.26167, indexed in Pubmed: 28884828.

3. Ayla Ş, Tunalı G, Bilgiç BE, et al. Antioxidant activity of CAPE (caffeic acid phenethyl ester) in vitro can protect human sperm deoxyribonucleic acid from oxidative damage. Acta Histochem. 2018; 120(2): 117-121, doi: 10.1016/j. acthis.2018.01.001, indexed in Pubmed: 29325972.

4. Barateiro A, Afonso V, Santos G, et al. S100B as a Potential Biomarker and Therapeutic Target in Multiple Sclerosis. Mol Neurobiol. 2016; 53(6): 3976-3991, doi: 10.1007/s12035015-9336-6, indexed in Pubmed: 26184632.

5. Caput D, Beutler B, Hartog K, et al. Identification of a common nucleotide sequence in the $3^{3}$-untranslated region of mRNA molecules specifying inflammatory mediators. Proc Natl Acad Sci U S A. 1986; 83(6): 1670-1674, indexed in Pubmed: 2419912.

6. Cargnello M, Roux PP. Activation and function of the MAPKs and their substrates, the MAPK-activated protein kinases. Microbiol Mol Biol Rev. 2011; 75(1): 50-83, doi: 10.1128/ MMBR.00031-10, indexed in Pubmed: 21372320.

7. Carlos TM, Clark RS, Franicola-Higgins D, et al. Expression of endothelial adhesion molecules and recruitment of neutrophils after traumatic brain injury in rats. J Leukoc Biol. 1997; 61(3): 279-285, indexed in Pubmed: 9060450.

8. Chen J, Leskov IL, Yurdagul A, et al. Recruitment of the adaptor protein Nck to PECAM-1 couples oxidative stress to canonical NF- $\kappa$ B signaling and inflammation. Sci Signal. 2015; 8(365): ra20, doi: 10.1126/scisignal.2005648, indexed in Pubmed: 25714462.

9. Chen Z, Tzima E. PECAM-1 is necessary for flow-induced vascular remodeling. Arterioscler Thromb Vasc Biol. 2009; 29(7): 1067-1073, doi: 10.1161/ATVBAHA.109.186692. indexed in Pubmed: 19390054.

10. Choi JH, Roh KH, Oh H, et al. Caffeic acid phenethyl ester lessens disease symptoms in an experimental autoimmune uveoretinitis mouse model. Exp Eye Res. 2015; 134: 53-62, doi: 10.1016/j. exer.2015.03.014, indexed in Pubmed: 25795054.

11. Coso OA, Chiariello M, Yu JC, et al. The small GTP-binding proteins Rac1 and Cdc42 regulate the activity of the JNK/SAPK signaling pathway. Cell. 1995; 81(7): 1137-1146, indexed in Pubmed: 7600581.

12. Deddens $L H$, van Tilborg GAF, van der Toorn A, et al. PECAM1-targeted micron-sized particles of iron oxide as MRI contrast agent for detection of vascular remodeling after cerebral ischemia. Contrast Media Mol Imaging. 2013; 8(5): 393-401, doi: 10.1002/cmmi.1536, indexed in Pubmed: 23740809.

13. Demeule $M$, Labelle $M$, Régina $A$, et al. Isolation of endothelial cells from brain, lung, and kidney: expression of the multidrug resistance P-glycoprotein isoforms. Biochem Biophys Res Commun. 2001; 281(3): 827-834, doi: 10.1006/ bbrc.2001.4312, indexed in Pubmed: 11237734.

14. Draper HH, Hadley M. Malondialdehyde determination as index of lipid Peroxidation. Methods Enzymol. 1990: 421-431, doi: 10.1016/0076-6879(90)86135-i.

15. Duan S, Shao G, Yu L, et al. Angiogenesis contributes to the neuroprotection induced by hyperbaric oxygen preconditioning against focal cerebral ischemia in rats. Int J Neurosci. 2015; 125(8): 625-634, doi: 10.3109/00207454.2014.956 101, indexed in Pubmed: 25171223.

16. Fukuda K, Aihara N, Sagar SM, et al. Purkinje cell vulnerability to mild traumatic brain injury. J Neurotrauma. 1996; 13(5): 255-266, doi: 10.1089/neu.1996.13.255, indexed in Pubmed: 8797175.
17. Gahmberg CG, Tolvanen M, Kotovuori P. Leukocyte adhesion--structure and function of human leukocyte beta2integrins and their cellular ligands. Eur J Biochem. 1997; 245(2): 215-232, indexed in Pubmed: 9151947.

18. Greenwood J, Etienne-Manneville S, Adamson P, et al. Lymphocyte migration into the central nervous system: implication of ICAM-1 signalling at the blood-brain barrier. Vascul Pharmacol. 2002; 38(6): 315-322, indexed in Pubmed: 12529926.

19. Gyoneva S, Ransohoff RM. Inflammatory reaction after traumatic brain injury: therapeutic potential of targeting cell-cell communication by chemokines. Trends Pharmacol Sci. 2015; 36(7): 471-480, doi: 10.1016/j.tips.2015.04.003, indexed in Pubmed: 25979813.

20. Haines JD, Fragoso G, Hossain S, et al. p38 Mitogen-activated protein kinase regulates myelination. J Mol Neurosci. 2008; 35(1): 23-33, doi: 10.1007/s12031-007-9011-0, indexed in Pubmed: 17994198.

21. Hu M, Zhang Y, Feng J, et al. Uterine progesterone signaling is a target for metformin therapy in PCOS-like rats. J Endocrinol. 2018; 237(2): 123-137, doi: 10.1530/JOE-18-0086, indexed in Pubmed: 29535146.

22. Huang $C, C a o Z, M a$ J, et al. AKR1B10 activates diacylglycerol (DAG) second messenger in breast cancer cells. Mol Carcinog. 2018; 57(10): 1300-1310, doi: 10.1002/mc.22844, indexed in Pubmed: 29846015.

23. Hwang InK, Kim DW, Yoo KY, et al. Ischemia-induced changes of platelet endothelial cell adhesion molecule-1 in the hippocampal CA1 region in gerbils. Brain Res. 2005; 1048(1-2): 251-257, doi: 10.1016/j.brainres.2005.04.049, indexed in Pubmed: 15913570.

24. Kaminska B, Gozdz A, Zawadzka M, et al. MAPK signal transduction underlying brain inflammation and gliosis as therapeutic target. Anat Rec (Hoboken). 2009; 292(12): 1902-1913, doi: 10.1002/ar.21047, indexed in Pubmed: 19943344.

25. Kaur C, Sivakumar V, Zou Z, et al. Microglia-derived proinflammatory cytokines tumor necrosis factor-alpha and interleukin-1 beta induce Purkinje neuronal apoptosis via their receptors in hypoxic neonatal rat brain. Brain Struct Funct. 2014; 219(1): 151-170, doi: 10.1007/s00429-0120491-5, indexed in Pubmed: 23262920.

26. Kerman M, Kanter M, Coşkun KK, et al. Neuroprotective effects of caffeic acid phenethyl ester on experimental traumatic brain injury in rats. J Mol Histol. 2012; 43(1): 49-57, doi: 10.1007/s10735-011-9376-9, indexed in Pubmed: 22124729

27. Kyosseva SV. Mitogen-activated protein kinase signaling. Int Rev Neurobiol. 2004; 59: 201-220, doi: 10.1016/S00747742(04)59008-6, indexed in Pubmed: 15006489.

28. Lavoie JN, L'Allemain G, Brunet A, et al. Cyclin D1 expression is regulated positively by the $\mathrm{p} 42 / \mathrm{p} 44 \mathrm{MAPK}$ and negatively by the p38/HOGMAPK pathway. J Biol Chem. 1996; 271(34): 20608-20616, indexed in Pubmed: 8702807.

29. Lertkiatmongkol $\mathrm{P}$, Liao D, Mei H, et al. Endothelial functions of platelet/endothelial cell adhesion molecule-1 (CD31). Curr Opin Hematol. 2016; 23(3): 253-259, doi: 10.1097/ $\mathrm{MOH} .0000000000000239$, indexed in Pubmed: 27055047.

30. Mandyam CD, Villalpando EG, Steiner NL, et al. Platelet endothelial cell adhesion molecule- 1 and oligodendrogenesis: significance in alcohol use disorders. Brain Sci. 2017; 7(10), doi: 10.3390/brainsci7100131, indexed in Pubmed: 29035306.

31. Mao LM, Wang JQ. Synaptically localized mitogen-activated protein kinases: local substrates and regulation. Mol Neurobiol. 2016; 53(9): 6309-6315, doi: 10.1007/s12035-0159535-1, indexed in Pubmed: 26567109.

32. Marmarou A, Foda MA, van den Brink W, et al. A new model of diffuse brain injury in rats. Part I: Pathophysiology and biomechanics. J Neurosurg. 1994; 80(2): 291-300, doi: 10.3171/jns.1994.80.2.0291, indexed in Pubmed: 8283269. 
33. Minden A, Lin A, Claret FX, et al. Selective activation of the JNK signaling cascade and c-Jun transcriptional activity by the small GTPases Rac and Cdc42Hs. Cell. 1995; 81(7): 1147-1157, indexed in Pubmed: 7600582.

34. Murohara T, Delyani JA, Albelda SM, et al. Blockade of platelet endothelial cell adhesion molecule- 1 protects against myocardial ischemia and reperfusion injury in cats. J Immunol. 1996; 156(9): 3550-3557, indexed in Pubmed: 8617985.

35. Nguyen V, Sabeur K, Maltepe E, et al. Sonic hedgehog agonist protects against complex neonatal cerebellar injury. Cerebellum. 2018; 17(2): 213-227, doi: 10.1007/s12311-017-08950 , indexed in Pubmed: 29134361.

36. Pabón MM, Acosta S, Guedes VA, et al. Brain region-specific histopathological effects of varying trajectories of controlled cortical impact injury model of traumatic brain injury. CNS Neurosci Ther. 2016; 22(3): 200-211, doi: 10.1111/ cns.12485, indexed in Pubmed: 26775604.

37. Paglia DE, Valentine WN. Studies on the quantitative and qualitative characterization of erythrocyte glutathione peroxidase. J Lab Clin Med. 1967; 70(1): 158-169, indexed in Pubmed: 6066618.

38. Potts MB, Adwanikar H, Noble-Haeusslein LJ. Models of traumatic cerebellar injury. Cerebellum. 2009; 8(3): 211-221, doi: 10.1007/s12311-009-0114-8, indexed in Pubmed: 19495901.

39. Privratsky JR, Newman PJ. PECAM-1: regulator of endothelial junctional integrity. Cell Tissue Res. 2014; 355(3): 607-619, doi: 10.1007/s00441-013-1779-3, indexed in Pubmed: 24435645.

40. Rose BA, Yokota T, Chintalgattu V, et al. Cardiac myocyte p38 $\alpha$ kinase regulates angiogenesis via myocyte-endothelial cell cross-talk during stress-induced remodeling in the heart. J Biol Chem. 2017; 292(31): 12787-12800, doi: 10.1074/jbc. M117.784553, indexed in Pubmed: 28637870.

41. Rosenblum WI, Murata S, Nelson GH, et al. Anti-CD31 delays platelet adhesion/aggregation at sites of endothelial injury in mouse cerebral arterioles. Am J Pathol. 1994; 145(1): 33-36, indexed in Pubmed: 8030753.

42. Roy AR, Delgado-Olguin P. Visualizing the vascular network in the mouse embryo and yolk sac. Methods Mol Biol. 2018; 1752: 11-16, doi: 10.1007/978-1-4939-7714-7_2, indexed in Pubmed: 29564758.

43. Rubinfeld $H$, Seger R. The ERK cascade as a prototype of MAPK signaling pathways. Methods Mol Biol. 2004; 250: 1-28, doi: 10.1385/1-59259-671-1:1, indexed in Pubmed: 14755077.

44. Sahu V, Nigam L, Agnihotri V, et al. Diagnostic significance of p38 isoforms (p38 $\alpha, \mathrm{p} 38 \beta, \mathrm{p} 38 \gamma, \mathrm{p} 38 \delta)$ in head and neck squamous cell carcinoma: comparative serum level evaluation and design of novel peptide inhibitor targeting the same. Cancer Res Treat. 2019; 51(1): 313-325, doi: 10.4143/ crt.2018.105, indexed in Pubmed: 29747487.

45. Sari E, Bakar B, Sarkarati B, et al. Effectiveness of dimethylsulfoxide on the survival and volume preservation of autologous fat graft tissue: a preliminary study. Aesthet Surg J. 2016; 36(2): NP58NP67, doi: 10.1093/asj/sjv119, indexed in Pubmed: 26242854.

46. Seo TB, Kim BK, Ko IG, et al. Effect of treadmill exercise on Purkinje cell loss and astrocytic reaction in the cerebellum after traumatic brain injury. Neurosci Lett. 2010; 481(3): 178-182, doi: 10.1016/j.neulet.2010.06.087, indexed in Pubmed: 20603186.

47. Springer T. Adhesion receptors of the immune system. Nature. 1990; 346(6283): 425-434, doi: 10.1038/346425a0.

48. Sun L, Zou LX, Wang J, et al. Mucin 4 gene silencing reduces oxidative stress and calcium oxalate crystal formation in renal tubular epithelial cells through the extracellular signal-regulated kinase signaling pathway in nephrolithiasis rat model. Kidney Blood Press Res. 2018; 43(3): 820-835, doi: 10.1159/000490136, indexed in Pubmed: 29843125.

49. Sun Y, Oberley LW, Li Y. A simple method for clinical assay of superoxide dismutase. Clin Chem. 1988; 34(3): 497-500, indexed in Pubmed: 3349599.
50. Tan J, Liu D, Lv X, et al. MAPK mediates inflammatory response and cell death in rat pulmonary microvascular endothelial cells in an ischemia-reperfusion model of lung transplantation. J Heart Lung Transplant. 2013; 32(8): 823-831, doi: 10.1016/j.healun.2013.05.005, indexed in Pubmed: 23747218.

51. Vaporciyan AA, DeLisser HM, Yan HC, et al. Involvement of platelet-endothelial cell adhesion molecule-1 in neutrophil recruitment in vivo. Science. 1993; 262(5139): 1580-1582, indexed in Pubmed: 8248808.

52. Wada T, Penninger JM. Mitogen-activated protein kinases in apoptosis regulation. Oncogene. 2004; 23(16): 2838-2849, doi: 10.1038/sj.onc.1207556, indexed in Pubmed: 15077147.

53. Waskiewicz AJ, Cooper JA. Mitogen and stress response pathways: MAP kinase cascades and phosphatase regulation in mammals and yeast. Curr Opin Cell Biol. 1995; 7(6): 798-805, indexed in Pubmed: 8608010.

54. Winzen R, Kracht M, Ritter B, et al. The p38 MAP kinase pathway signals for cytokine-induced mRNA stabilization via MAP kinase-activated protein kinase 2 and an AUrich region-targeted mechanism. EMBO J. 1999; 18(18): 4969-4980, doi: 10.1093/emboj/18.18.4969, indexed in Pubmed: 10487749 .

55. Wolters TL, Netea MG, Hermus AR, et al. IGF1 potentiates the pro-inflammatory response in human peripheral blood mononuclear cells via MAPK. J Mol Endocrinol. 2017; 59(2): 129-139, doi: 10.1530/JME-17-0062, indexed in Pubmed: 28611056

56. Wu N, Kurosu T, Oshikawa G, et al. PECAM-1 is involved in $B C R / A B L$ signaling and may downregulate imatinib-induced apoptosis of Philadelphia chromosome-positive leukemia cells. Int J Oncol. 2013; 42(2): 419-428, doi: 10.3892/ ijo.2012.1729, indexed in Pubmed: 23233201.

57. Xia Z, Dickens M, Raingeaud J, et al. Opposing effects of ERK and JNK-p38 MAP kinases on apoptosis. Science. 1995; 270(5240): 1326-1331, indexed in Pubmed: 7481820.

58. Xiao H, Liu X, Wang Y, et al. Angiotensin(17) prevents lipopolysaccharideinduced hepatocellular inflammatory response by inhibiting the p38MAPK/AP1 signaling pathway. Mol Med Rep. 2018; 17(4): 5492-5497, doi: 10.3892/mmr.2018.8527, indexed in Pubmed: 29393446.

59. Xie Y, Muller WA. Molecular cloning and adhesive properties of murine platelet/endothelial cell adhesion molecule 1. Proc Natl Acad Sci U S A. 1993; 90(12): 5569-5573, indexed in Pubmed: 8516303.

60. Yang G, Li T, Xu J, et al. Mitogen-activated protein kinases regulate vascular reactivity after hemorrhagic shock through myosin light chain phosphorylation pathway. J Trauma Acute Care Surg. 2013; 74(4): 1033-1043, doi: 10.1097/ TA.0b013e31828586a2, indexed in Pubmed: 23511142.

61. Yang SH, Sharrocks AD, Whitmarsh AJ. Transcriptional regulation by the MAP kinase signaling cascades. Gene. 2003; 320: 3-21, indexed in Pubmed: 14597384.

62. Zhang J, Zhao D, Na N, et al. Renoprotective effect of erythropoietin via modulation of the STAT6/MAPK/NF- $\kappa$ B pathway in ischemia/reperfusion injury after renal transplantation. Int J Mol Med. 2018; 41(1): 25-32, doi: 10.3892/ijmm.2017.3204, indexed in Pubmed: 29115389.

63. Zhang $X$, Liu J, Zhang P, et al. Silibinin induces G1 arrest, apoptosis and JNK/SAPK upregulation in SW1990 human pancreatic cancer cells. Oncol Lett. 2018; 15(6): 9868-9876, doi: 10.3892/ol.2018.8541, indexed in Pubmed: 29805688.

64. Zhang YY, Kong LQ, Zhu XD, et al. CD31 regulates metastasis by inducing epithelial-mesenchymal transition in hepatocellular carcinoma via the ITGB1-FAK-Akt signaling pathway. Cancer Lett. 2018; 429: 29-40, doi: 10.1016/j. canlet.2018.05.004, indexed in Pubmed: 29746931.

65. Zhu J, Ji Y, Yu Y, et al. Knockdown of serine/threonine protein phosphatase 5 enhances gemcitabine sensitivity by promoting apoptosis in pancreatic cancer cells . Oncol Lett. 2018; 15(6): 8761-8769, doi: 10.3892/ol.2018.8363, indexed in Pubmed: 29805615. 